\title{
Clinical aspects of demodicosis in veterinary and human medicine
}

\author{
DAWID JAŃCZAK, ANNA RUSZCZAK*, ILONA KASZAK*, \\ ELŻBIETA GOŁĄB, KAROLINA BARSZCZ**
}

\author{
Division of Parasitology, National Institute of Public Health, National Institute of Hygiene, \\ Chocimska 24, 00-791 Warsaw, Poland \\ *Department of Small Animal Diseases with Clinic, **Department of Morphological Sciences, \\ Faculty of Veterinary Medicine, Warsaw University of Life Sciences, Nowoursynowska 159c, 02-776 Warsaw, Poland
}

Jańczak D., Ruszczak A., Kaszak I., Gołąb E., Barszcz K.

\section{Clinical aspects of demodicosis in veterinary and human medicine}

Summary

Mites from the genus Demodex are ectoparasites of many mammals, including humans. There are over 100 Demodex species, which demonstrate strong specificity in host selection (Tab. 1). The mites are common in humans. It has been estimated that up to $60 \%$ of adults may be infected, but in most cases no symptoms of the disease are present. Demodex multiplication inside sebaceous glands and hair follicles can lead to skin disease in both humans and animals. In humans, the main problem is ocular demodicosis, which can cause chronic conjunctivitis and blepharitis. In this paper, we present the biology and epidemiology of Demodex species in humans as well as in domestic and farm animals. Characteristic lesions, diagnostics and treatment of demodicosis are also described.

Keywords: Demodex spp., human, dogs, cats, farm animals, wild animals

There are over 100 mite species from the genus Demodex worldwide inhabiting the skin of most mammals (29). Those parasites have strong specificity in their host selection. Occasionally it happens that two different Demodex species inhabit the same host occupying different habitats (47). Due to the high specificity of the host, Demodex species do not pose a threat to human health.

Mites from the genus Demodex belong to the class Arachnids (Arachnida), subclass Acari (Acarina), family Demodecidae. Demodex species have been described in many species of mammals. These parasites inhabit hair follicles and sebaceous gland ducts, and can often cause their extension or obstruction, which can lead to inflammation.

Demodex inhabits about $60 \%$ of humans, although in most cases its presence does not give any symptoms of the infection (43). The percentage of infected individuals increases with age: it is nearly $84 \%$ for people in their sixties and can be up to $100 \%$ among those older than 80 (56). In humans, demodicosis affects mainly the face, especially the area of the eyebrows, eyelids, nostrils and forehead. Less often, it is diagnosed in the skin of the chest or in the genital area (48).
In veterinary medicine, canine demodicosis and some cases of feline demodicosis are the biggest clinical problems. In veterinary clinics of exotic and non-domesticated animals, demodicosis is observed in hamsters, rats and other mammals. Demodicosis in animals affects various skin areas. In dogs, it is most often found in skin around the eyes, nasal bridge or cheek skin folds (45).

\section{Biology and morphology}

The body of mites from the genus Demodex is divided into three segments: front (gnatosoma) with mouthparts, middle (podosoma) with legs and final (opistosoma), which is worm-shaped and often has a striated surface.

The life cycle of parasites from the genus Demodex can be divided into 5 stages: egg, larva, protonymph, nymph and adult forms. The development time for D. folliculorum (human Demodex) under laboratory conditions is about 14 days, and in nature may take even longer (16). An adult female after mating, which takes place in the ostium of a hair follicle, lays a couple to over a dozen eggs (Fig. 1). From the spindle-shaped egg, a legless larva develops after six hours, and after 
36 hours a protonymph arises, which has 3 pairs of appendages or poorly chitinized legs (Fig. 2). The protonymph has more marked striations of opistosoma compared to nymphs and adults. The protonymph is converted into the nymph after about 3 days, and its size depends on the species of Demodex. Adult males or females develop from the nymphs after 2-3 days (44).

Adult mites have 4 pairs of well-developed legs. The striations of opistosoma are practically invisible, and females are bigger than males. Mites from the genus Demodex feed on the secretion of sebaceous glands and cells lining sebaceous glands and hair follicles (35).

\section{Importance for human medicine}

Demodex spp. are diagnosed in humans all over the world. In humans, the cause of demodicosis is invasion by one or two species simultaneously: Demodex folliculorum and Demodex brevis (56). Demodex folliculorum is present in hair follicles. Adults found in eyelashes can even have a length of 0.3-0.4 $\mathrm{mm}$ and are longer than $D$. folliculorum found in other body parts, including the skin of the chest or genital area. D. brevis is found in sebaceous gland ducts. It is smaller - adults reach a length of 0.2-0.3 mm (17). Although demodicosis is a skin disease, it can mask many other inflammatory dermatoses, such as folliculitis, acne rosacea or perioral dermatitis. In human dermatology, two types of demodicosis can be distinguished: primary and secondary. Primary demodicosis is manifested by inflammation of sebaceous glands, follicular or macular inflammation of the skin around the lips, nostrils and eyes. In the course of primary demodicosis, focal lesions of skin around the mouth, eyes and ear canal can be observed. These changes can be red, slightly scaly and protruding above the skin surface. Ocular demodicosis is characterized by the presence of chronic conjunctivitis and blepharitis, sensation of a foreign body under the eyelids and sometimes dry eye syndrome. Invasion of the ear canal by mites of the Demodex species can be manifested by the inflammation of the external ear canal or the tympanic membrane.

Secondary demodicosis develops mainly due to taking immunosuppressive drugs like glucocorticoids, both in general and topical treatment (13). Increasingly, it is claimed that Demodex spp. mites cause the persistence of acne rosacea, as a late factor of this dermatosis (1).

Primary demodicosis usually affects people over the age of 40. The incidence of demodicosis in children and teenagers is rare, which may be related to the low secretion of sebum by sebaceous glands (56). In young people, the development of secondary demodicosis may occur due to an immunosuppressive therapy. In these cases, the course of the disease is more aggressive and disseminated (13).

Research carried out at the Pomeranian Medical University in Szczecin in a group of 95 patients with

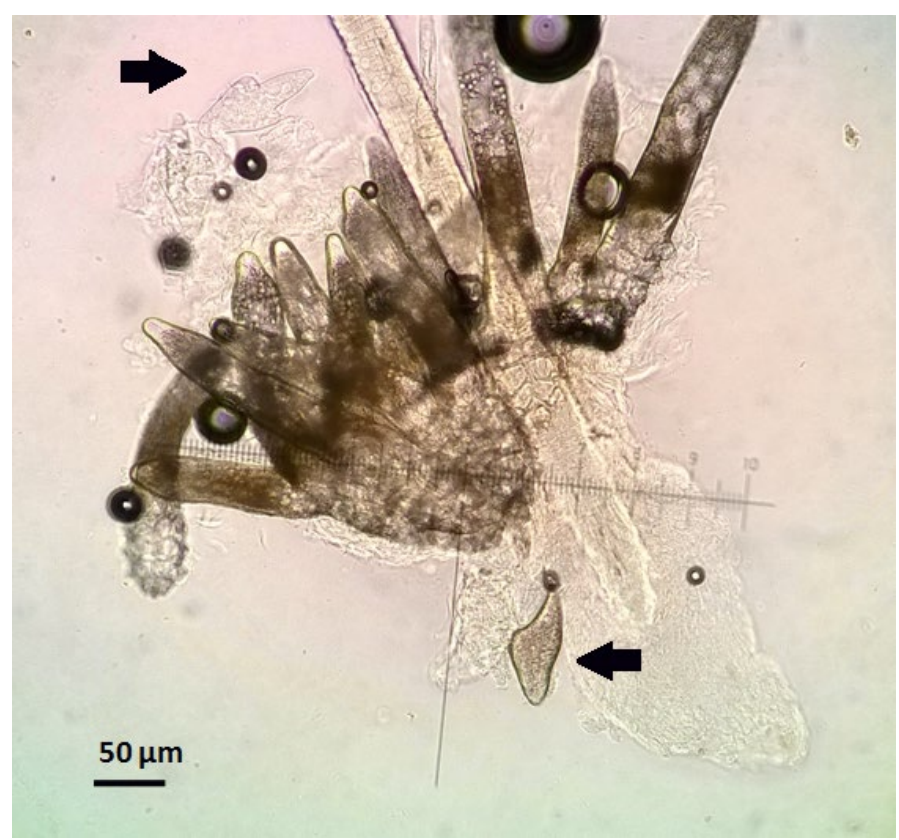

Fig. 1. Adult Demodex folliculorum mites and their eggs (arrows) found on a human eyelash

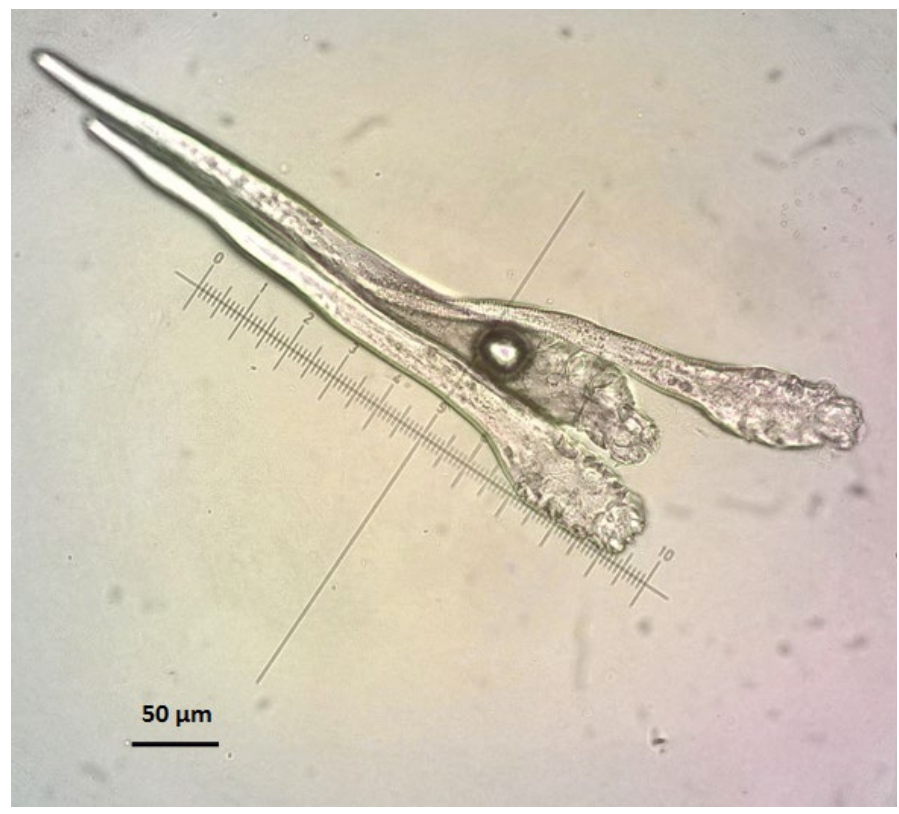

Fig. 2. Larval stage (protonymph) of Demodex folliculorum found on a human eyelash

a weakened immune system showed the presence of mites on the eyelashes in $20 \%$ of the patients. None of these patients was diagnosed with typical symptoms of ocular demodicosis, such as blepharitis, sensitivity to light, excessive tearing or loss of eyelashes. In the study control group Demodex was detected in $22.9 \%$ of people. The authors suggest that these results may indicate that immunosuppression does not significantly affect the incidence of invasion (34). Research carried out in Wroclaw among patients of the Regional Hospital, students of the Medical University and patients of the Clinic of Prevention, Treatment and Therapy of Addictions for the MONAR association Youth, showed a $41 \%$ prevalence of Demodex inva- 
sion (57). The percentage of the infected among the hospital patients was the highest, at $54.7 \%$, and among healthcare workers it amounted to about 40\%. D. folliculorum was found significantly more often $(81.5 \%)$ than $D$. brevis $(34.5 \%)$. In $15.1 \%$ of the people examined, a coinvasion by both mite species was found. Furthermore, there was no significant difference between the prevalence of parasites in women (42.1\%) and men $(39.7 \%)$. It was recognized, however, that this parasite affects more often people over the age of 50 .

Conjunctivitis was reported in $59.7 \%$ of the people examined. The main complaint described by the patients was itching $(38.3 \%)$ and burning $(30.7 \%)$ of the eyelids. Mites of Demodex species were diagnosed in $41.6 \%$ of people reporting symptoms associated with conjunctivitis. In a similar proportion $(40.2 \%)$, people who did not report any symptoms or discomfort around the eyes were also diagnosed with mites, which, according to the authors, suggests that the course of the invasion is very frequently asymptomatic (57).

A study was carried out among a group of 121 patients of a Medical Centre in Tarnów suffering from ocular lesions. Thirty-six patients were diagnosed with meibomitis. A significant correlation was found between meibomitis and the presence of Demodex in eyelashes. The parasites were found in $91.67 \%$ of people from this group. Demodex was detected more frequently in women than in men, especially in age groups 31-40 and 51-60 years (55).

The research made in the Medical Centre in Tarnów in a group of 62 patients, 28 of which declared discomfort while using contact lenses and 34 without this complaint, showed the presence of Demodex in $92.86 \%$ of the patients that were no longer using contact lenses because of discomfort (54).

A high percentage of Demodex infections occur among patients with dry eye syndrome, photophobia, sensation of a foreign body under the eyelids, excessive tearing, blepharitis or conjuntivitis.

These symptoms are frequently misdiagnosed as allergenic, bacterial or viral conjuctivitis. Unfortunately, Demodex is rarely considered in the differential diagnosis of etiological factors of this kind of disorders, and the treatment is frequently incorrect (43).

\section{Importance for veterinary medicine}

Dogs. In dogs, the most commonly reported mite species is Demodex canis, which lives in hair follicles, sebaceous glands and sebaceous gland ducts. Furthermore, there is a species of Demodex injai, which also lives in hair follicles and sebaceous glands, but is more often found in adult dogs diagnosed with iatrogenic Cushing's syndrome and hypothyroidism $(18,40)$.

A third species, Demodex cornei, has been isolated and described by macroscopic and molecular methods. Unlike the other two species, it is found in the keratin-
Tab. 1. Demodex species present in animals

\begin{tabular}{|c|c|c|}
\hline Host & Demodex species & Occurrence \\
\hline \multirow{3}{*}{ Domestic dog (Canis familiaris) } & D. canis & $\begin{array}{l}\text { France } \\
\text { Brazil } \\
\text { China } \\
\text { Spain } \\
\text { Poland } \\
\text { Greece }\end{array}$ \\
\hline & D. injai & $\begin{array}{l}\text { Italy } \\
\text { United States } \\
\text { Poland }\end{array}$ \\
\hline & D. cornei & $\begin{array}{l}\text { India } \\
\text { Poland } \\
\text { Greece } \\
\text { China }\end{array}$ \\
\hline \multirow{3}{*}{ Domestic cat (Felis catus) } & D. cati & $\begin{array}{l}\text { Austria } \\
\text { United States } \\
\text { India } \\
\text { New Caledonia }\end{array}$ \\
\hline & D. gatoi & $\begin{array}{l}\text { Austria } \\
\text { United States } \\
\text { Finland }\end{array}$ \\
\hline & D. felis & United States \\
\hline \multirow{2}{*}{$\begin{array}{l}\text { Golden hamster (Mesocricetus } \\
\text { auratus) }\end{array}$} & D. criceti & \multirow{2}{*}{ Turkey } \\
\hline & D. aurati & \\
\hline \multirow{2}{*}{ Horse (Equus caballus) } & D. equi & \multirow{2}{*}{ United States } \\
\hline & D. caballi & \\
\hline Cow (Bos taurus) & D. bovis & $\begin{array}{l}\text { Czech Republic } \\
\text { Canada }\end{array}$ \\
\hline Sheep (Ovis aries) & D. ovis & $\begin{array}{l}\text { Israel } \\
\text { Czech Republic }\end{array}$ \\
\hline Goat (Capra hircus) & D. caprae & $\begin{array}{l}\text { Czech Republic } \\
\text { Ethiopia } \\
\text { China }\end{array}$ \\
\hline \multirow{3}{*}{ Brown rat (Rattus norvegicus) } & D. ratti & \multirow{3}{*}{ Czech Republic } \\
\hline & D. norvegicus & \\
\hline & D. ratticola & \\
\hline \multirow{2}{*}{ House mouse (Mus musculus) } & D. arvicolae & \multirow{2}{*}{ Poland } \\
\hline & D. flagellurus & \\
\hline Common vole (Microtus arvalis) & D. microti & Poland \\
\hline Big brown bat (Eptesicus fuscus) & Demodex sp. & United States \\
\hline European otter (Lutra Iutra) & D. Iutrae & Poland \\
\hline Gray seal (Phoca vitulina) & Demodex sp. & Hungary \\
\hline \multirow{3}{*}{ Bison (Bison bonasus) } & D. bisonasus & \multirow{3}{*}{ Poland } \\
\hline & D. bovis & \\
\hline & Demodex sp. & \\
\hline Wild boar (Sus scrofa) & D. phylloides & Poland \\
\hline
\end{tabular}

ized layer of the epidermis and is a common cause of seborrheic dermatitis in dogs $(46,47)$.

All 3 species of the genus Demodex that parasitize canine skin have been found in Poland (29). Moreover, D. cornei has also been found among dogs in China, Greece and India $(11,50,53)$.

Demodicosis is a frequent dermatological problem in dogs. It affects mostly puppies at the age of 3 to 6 months, in which the immune system is not fully de- 
veloped. Puppies usually get infected by their mothers, so the infection begins in early life. Small populations of Demodex live on the skin of healthy dogs, but only disease and immunossuppresion cause the parasites to propagate in hair follicles and sebaceous glands, and thus skin lesions may appear. Local canine demodicosis is manifested by reddened foci, alopecias, the thickening of skin around the eyes, muzzle and limbs, and by bones eminences. Very often, these dogs recover spontaneously when sexual maturity is reached. However, sometimes general demodicosis can develop, which is difficult to treat and can result in the animal's death. Generalized juvenile demodicosis affects dogs under 18 months, whereas generalized demodicosis of adult dogs affects animals older than 4 years. In this form of demodicosis, the skin becomes dry and rough, or pustules develop. Superinfection of damaged skin with bacteria from the Staphylococcus species and pyoderma frequently occur (6).

Cats. In cats, 3 mite species have been reported: Demodex cati, Demodex gatoi and Demodex felis. Demodex cati is the species most often diagnosed in feline demodicosis. Invasions of $D$. cati are described in North America, Europe, Australia, Africa, as well as in India and New Caledonia (5). Feline demodicosis is a rarely described disease. It usually affects cats over 1 year of age and is very rarely reported in kittens.

Most of the cases described have been associated with other diseases, such as feline immunodeficiency virus (FIV), feline leukemia virus (FeLV), Mycoplasma haemoelis infection, neoplastic diseases, diabetes and long term general or topical glucocorticoid therapy (4). In cats, local demodicosis can be recognized in the form of pustules, focally reddened skin or alopecias. The parasite, found in hair follicles and sebaceous glands, causes lesions on the skin of the head and ear canals, and sometimes on the skin of the neck. Generalized demodicosis in cats is described when skin lesions are noticed in more then 5 places, or when lesions appear in different body parts. Analysis of numerous cases of feline demodicosis has not shown any correlation with sex or breed. It has also been found that, in the case of generalized demodicosis, pyoderma rarely develops in cats (5).

Demodex gatoi is rarely located in hair follicles, as it lives in the external layer of skin, and more specifically, in the keratinized layer, causing focal desquamation lesions and alopecias in different body parts, including the abdomen. D. gatoi also results in pruritus, which stimulates the cat to lick the lesions, causing them to deteriorate. Demodicosis caused by D. gatoi is highly contagious and frequently described in houses in which many cats live together $(49,52)$.

Molecular studies have confirmed the occurrence of the mite species Demodex felis in cats (51).

Pet rodents. Demodicosis is a rarely diagnosed skin disease in domestic rodents. In the golden hamster, two mite species have been described:Demodex criceti and

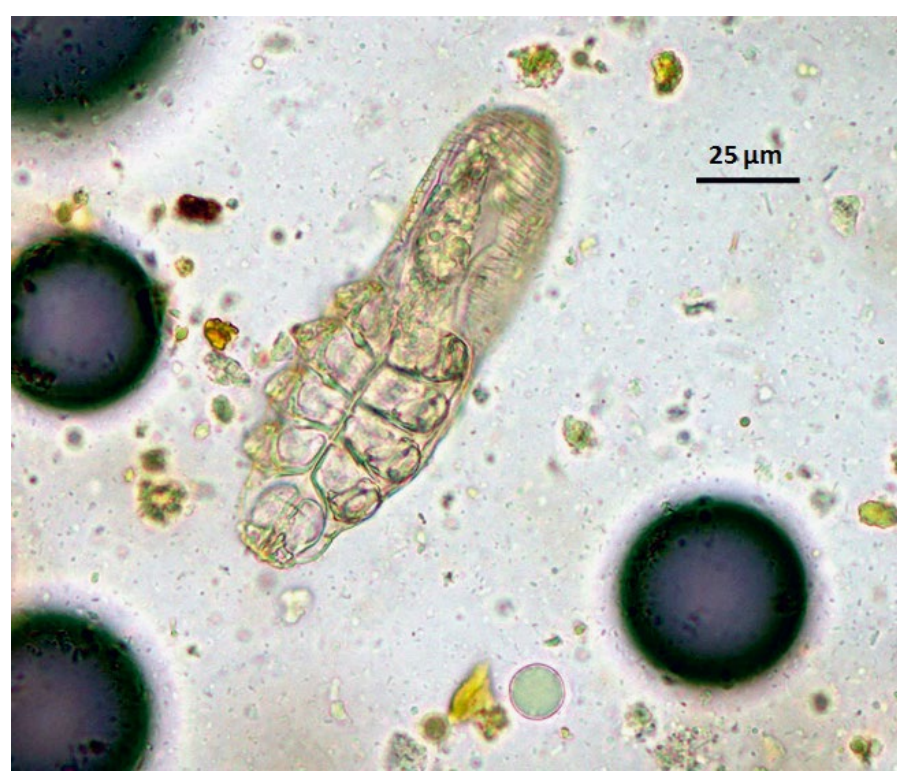

Fig. 3. Demodex criceti found in the feces of a golden hamster (Mesocricetus auratus)

Demodex aurati. Demodex criceti is a mite living in the keratinized layer of the epidermis (Fig. 3). D. aurati is highly pathogenic and lives in hair follicles and sebaceous glands. Demodex invasion in hamsters is manifested by pruritus, alopecias in the lumbosacral part of the body. Letarghy and emaciation may be present as well (31).

Horses. In horses, two mite species occur: D. equi and D. caballi. Demodex equi lives in hair follicles, especially in the skin of the neck, back, the area of the blades and distal parts of thoracic limbs. D. caballi, on the other hand, settles in the sebaceous glands of the eyelids and in the frontal nostril area. Demodicosis in horses can be manifested by irregular alopecias or nodular skin lesions. Despite the presence of the parasite in the skin of the eyelids, neither conjunctivitis nor blepharitis due to Demodex invasion have been diagnosed. It has been observed that symptomatic equine demodicosis is correlated with chronic glucocorticoid treatment and a dysfunction of the intermediate lobe of the pituitary gland $(3,37)$.

Farm ruminants. In cows, demodicosis is caused by Demodex bovis. The life cycle of $D$. bovis lasts from 18 to 24 days (40). Skin lesions have the form of intradermal nodules on the head, neck and back. Histopathological examination confirmed the presence of a very large of number of mites inside the nodules as well as lesions due to granulomatous inflammation (9).

In sheep, three mite species have been described: D. ovis, D. aries and one more species not completely specified. All three species live in hair follicles $(8,58)$.

In goats, invasions by $D$. caprae are described. This parasite causes skin lesions on the neck, back and thoracic limbs. The lesions have the form of nodules filled with a greasy, creamy mass, in which mites are located (19). Demodex caprae is found in goats in Europe and in Africa. Research in a group of 750 goats from Ethiopia showed that about $7 \%$ of animals 
were infected with $D$. caprae. The invasion of this mite affects mainly older animals and those in a poor body condition (38). The identification and molecular analysis of the gen cox 1 have made it possible to consider D. caprae as a separate species, phylogenetically independent of the other species from the genus Demodex (59).

Wild animals. The bison (Bison bonasus) is a frequent host of Demodex bisonasus and D. bovis (30, 32). Demodex bisonasus is found mainly in the skin in the area of the eyelids (30).

In wild boars (Sus scrofa), Demodex phylloides has been described, which lives in hair follicles, and its invasion is asymptomatic. This parasite has not been described in farm pigs (22).

In the United States, in the eastern part of the Tennessee state, one species of Demodex has been found in the skin of the prepuce in big brown bats (Eptesicus fuscus). A DNA analysis of the bat mite revealed that its genome sequence was $99.6 \%$ identical to the sequence of D. canis. However, the significantly different morphology of the mite living in bat skin led to its classification as a separate species (36).

A new mite species, Demodex lutrae, living in the skin of the head of the European otter (Lutra lutra) was described in Poland in 2014 (27). In 2016, in two males of the gray seal (Phoca vitulina) from a Hungarian zoo, skin lesions caused by an unknown mite of the Demodex species were noticed and effectively treated with amitraz (33).

In brown rats (Rattus norvegicus), three mite species have been described: Demodex ratti, Demodex norvegicus and Demodex ratticola, which occur in skin in many body parts. $D$. ratti is found in the skin of the fingers, eyelids and external ear canal. D. norvegicus lives in hair follicles in the area of the anus and genitals. D. ratticola, the smallest mite of the Demodex genus found in rats, inhabits the area of the mouth and the top of the muzzle (7).

In mice (Mus musculus), D. arvicolae has been found in the skin of the eyelids and around the eyes, whereas D. flagellurus has been detected in the skin of the genital area. No pathological skin lesions in mice inhabited by these mite species have been described (25).

In a group of common voles (Microtus arvalis) from northern Poland, D. microti was found in the skin of the genital area. No pathological skin lesions were found in the skin of the infected animals (28).

\section{Diagnostics}

In the diagnostics of demodicosis, different techniques are used, including skin scrapings, the adhesive tape test, examination of hair and skin biopsies. The presence of mites is confirmed by microscopic examination of collected material.

Scrapings should be performed in such a way as to obtain the most material possible. For this purpose, a skin fold should be squeezed between fingers, and a sebaceous gland should be emptied. The material should be collected with a scalpel blade held at the right angle until the first blood drop appears. In order to visualize the parasites better, the material can be partly digested with a $5-10 \%$ potassium hydroxide solution.

In the adhesive tape test, the material for microscopic examination is collected by doing fingerprints from skin lesions. In addition, skin lesions can be covered by tape and then squeezed between fingers. After performing a couple of prints, the tape is stuck to a microscopic slide, and the preparation is observed with $4 \times$ and $10 \times$ magnification. The results of comparative studies confirm a higher sensitivity of the adhesive tape test to scrapings in the diagnosis of canine demodicosis (41).

In hair examination, hair pulled from the root can be placed into liquid paraffin or Hoyer's solution and then covered with a cover slip. Hoyer's solution dissolves squamous epithelial cells and blood clots, making the parasites and their eggs more visible (14). Hair examination is used mainly in the diagnosis of demodicosis in humans, whose eyelashes or eyebrows are collected for microscopic examination.

Mites detected and obtained by the microscopic method can be examined by analyzing molecular fragments of 16S rRNA or the mitochondrial fragment of the COI gene. The sequences obtained can be compared with those deposited in the GenBank database, which makes it possible to differentiate mite species and create phylogenetic maps of them $(21,59)$.

\section{Treatment}

In human medicine, topical medication in the form of eye ointments containing antibiotics like macrolides (erythromycin) or nitroimidazoles (metronidazole) are mainly used. Treatment of facial demodicosis or chronic blepharitis caused by Demodex is long and usually takes more than 5 months (43). The use of minocycline during 6 months seems to be effective. Good results are also obtained with products containing onion or camomile extracts, heparin or allantoin.

Secondary demodicosis related to acne rosacea is treated with orally administered metronidazole or ivermectin and topically administered cream containing lindane, crotamiton and permethrin $(15,23,48)$. According to the literature, herbal mixtures containing tea tree oil, fir or sage oil are effective as well $(12,43)$.

In veterinary medicine, there is a wide range of products used in treating animal demodicosis. The most commonly used preparations are ivermectin, selamectin, milbemycin oxime, doramectin, and moxidectin, as well as amitraz, which in appropriate concentrations is also used in large animals in the form of compresses. In cats, ointment containing calcium sulfate is used with different efficacy $(2,6,24)$. It should be noted that many of these preparations are not registered in Poland for use in domestic animals. Due to the fact that many dog breeds are sensitive to ivermectin, they should be pre-tested for the expression of the multidrug resistance 
gene (MDR1) in order to prevent fatal adverse effects after administration of ivermectin or its derivatives.

Ivermectin. In dogs, the most effective treatment of demodicosis is ivermectin administered orally or by subcutaneous injections at the dose range 0.2-0.6 mg/ $\mathrm{kg}$ b.w. An oral dose can be administered every day for up to 200 days. Injections are usually made every 7-10 days.

The dose for cats is $0.3 \mathrm{mg} / \mathrm{kg}$ b.w. administered weekly in four repetitions $(2,6,24)$.

In rodents, ivermectin is administered in subcutaneous injections at a dose of $0.2 \mathrm{mg} / \mathrm{kg} \mathrm{b.w}$. every 7-10 days (10).

Selamectin. Is a preparation whose efficacy in the treatment of demodicosis is slightly lower than that of ivermectin. The dose for dogs and cats is $6 \mathrm{mg} / \mathrm{kg} \mathrm{b.w}$. It is mainly used as a spot-on once a month or, in the case of a severe parasite invasion, every two weeks (27, $42)$. For rabbits, rodents or small mammals, a dose of $6-18 \mathrm{mg} / \mathrm{kg}$ b.w. is administered every two weeks (10).

Milbemycin. Preparations containing milbemycin oxime often appear to be as effective as ivermectin and have less side effects in prolonged use. The treatment regimen in dogs is $1-2 \mathrm{mg} / \mathrm{kg}$ b.w. administered orally every day for 3 months. If negative results of the microscopic examination of scrapings are obtained after 4 and 6 weeks, the treatment is continued at the same dose for 30 days $(24,42)$.

Doramectin. This preparation from the group of avermectins is used mainly in farm animals as a treatment against invasion by gastrointestinal and pulmonary nematodes and for the control of ectoparasites. So far, no universal treatment regimen of demodicosis has been described, but the dose of doramectin for dogs is $0.6 \mathrm{mg} / \mathrm{kg}$ b.w. in subcutaneous injections once a week. The treatment is continued for four weeks after obtaining negative results in microscopic examination of skin scraping (42).

Moxidectin. In Poland, this preparation is registered for dogs as a treatment against invasion by Demodex canis. It is available in the form of spot-on for use once a month at a dose of $2.5 \mathrm{mg} / \mathrm{kg}$ b.w. Research has shown that the effectiveness increases with the frequency of administration, for example, once a week or every two weeks $(2,24)$.

Amitraz. Is used in dogs and large animals, but rarely in cats and very small breed dogs because of a higher risk of adverse effects, such as sedation, drowsiness, hypothermia, bradycardia, shortness and weakening of breath, as well as neurological disorders. If these symptoms occur, an antidote is yohimbine at a dose of $0.1 \mathrm{mg} / \mathrm{kg} \mathrm{b.w}$. or atipamezole at a dose of $0.2 \mathrm{mg} / \mathrm{kg}$ m.c. Sometimes supportive treatment is also necessary. Amitraz is used as an $0.025 \%$ aqueous solution in the form of compresses every 14 days $(2,24)$. Amitraz can be used as a spot-on in combination with fipronil and (S)-metophren. Used once or twice a month, this preparation, is highly effective in treating generalized demodicosis (20). Amitraz in a concentration of $0.01 \%$ administered topically, has proved to be an effective treatment of demodicosis in gray seals (33).

Calcium sulphate. Ointment containing 2-3\% of calcium sulphate is effective in treatment of feline demodicosis caused by D. gatoi. The efficacy of the ointment is related to its keratolytic action and production of hydrogen sulfide and sulfur oxoacids. The ointment is applied once a week for 6 weeks. At this time, it is recommended for cats to wear an Elisabethan collar to prevent them from licking the ointment, which can cause gastrointestinal disorders (24).

\section{References}

1. Ali S. T., Alinia H., Feldman S. R.: The treatment of rosacea with topical ivermectin. Drug Today 2015, 50, 243-250.

2. Arsenovic M., Pezo L., Vasic N., Ciric R., Stefanovic M.: The main factors influencing canine demodicosis treatment outcome and determination of optimal therapy. Parasitol. Res. 2015, 114, 2415-2426.

3. Besch E. D., Griffiths H. J.: Demonstration of Demodex equi (Railliet, 1895) from a horse from Minnesota. J. Am. Vet. Med. Ass. 1956, 128, 82-83.

4. Bizikova P.: Localized demodicosis due to Demodex cati on the muzzle of two cats treated with inhalant glucocorticoids. Vet. Dermatol. 2014, 25, 222-225.

5. Bowman D. D.: Feline Clinical Parasitology. Iowa State University Press, Iowa 2002.

6. Bowman D. D.: Parazytologia weterynaryjna. Elsevier, Wrocław 2012

7. Bukva $V$ : : Demodex species (Acari: Demodecidae) parasitizing the brown rat, Rattus norvegicus (Rodentia): redescriptopn of Demodex ratti and description of D. norvegicus sp. n. and D. ratticola sp. n. Fol. Parasitol. 1995, 42, 149-160.

8. Bukva $V$ : Three species of the follicle mites (Acari: Demodecidae) parasitizing the sheep, Ovis aries L. Fol. Parasitol. 1990, 37, 81-91.

9. Bukva V., Vitovec J., Schandl V.: The first occurrence of demodicosis in cattle in Czechoslovakia. Vet. Med. - Praha 1985, 30, 515-520.

10. Carpenter J. W.: Exotic Animal Formulary, 4th edition. Elsevier Inc. Saunders, St. Louis Missouri 2013.

11. Chen C. A.: Short-tailed demodectic mite and Demodex canis infestation in a Chihuahua dog. Vet. Dermatol. 1995, 6, 227.

12. Chen W., Plewig G.: Human demodicosis: revisit and proposed classification. Brit. J. Dermatol. 2014, 170, 1219-1225.

13. Cheng A. M., Sheha H., Tseng S. C.: Recent advances on ocular Demodex infestation. Curr. Op. Ophtalmol. 2015, 26, 295-300.

14. Cielecka D., Sałamatin R., Garbacewicz A.: Zastosowanie płynu Hoyera do diagnostyki i badań morfologicznych niektórych pasożytów. Wiad. Parazytol. 2009, 55, 265-270.

15. Damian D., Rogers M.: Demodex infestation in a child with lekaemia: treatment with ivermectin and permethrin. Int. J. Dermatol. 2003, 42, 724-726.

16. Deryło A.: Parazytologia i akaroentomologia medyczna. PWN, Warszawa 2002.

17. Desch C., Nutting W. B.: Demodex folliculorum (Simon) and D. brevis (Akbulatova) of man: reevaluation. J. Parasitol. 1972, 58, 169-177.

18. Desch C. E., Hillier A.: Demodex injai: a new species of hair follicle mite (Acari: Demodecidae) from the domestic dog (Canidae). J. Med. Entomol. 2003, 40, 146-149.

19. Fleischer P., Lukesova D., Skrivanek M., Hofirek B., Stursa I.: First report of demodicosis in goats in the Czech Republic. Vet. Med. - Praha 1996, 41, 289-293.

20. Fourie J., Dumont P., Halos L., Beugent F., Pollmeier M.: Effiacy of a topical application of Certifect ${ }^{\circledR}$ (fipronil $6.26 \% \mathrm{w} / \mathrm{v}$, amitraz $7.48 \% \mathrm{w} / \mathrm{v}$, (S)-methoprene $5.63 \% \mathrm{w} / \mathrm{v}$ ) for the treatment of canine generalized demodicosis. Parasite 2013, 20, 1-6.

21. Frank L. A., Kania S. A., Chung K., Brahmbhatt R.: A molecular technique for the detection and differentiation of Demodex mites on cats. Vet. Dermatol. 2013, 24, 367-383.

22. Fryderyk S., Izdebska J. N.: Demodex phylloides (Acari, Demodecidae) as a specific parasite of Sus scrofa (Mammalia, Artiodactyla). Wiad. Parazytol. 2001, 47, 797-800.

23. Gerkowicz M., Baltaziak L., Puacz E.: Przewlekłe zapalenie brzegów powiek Klin. Oczna 2005, 107, 376-378.

24. Ghubash R.: Parasitic Miticidal Therapy. Clin. Tech. Sm. Anim. Pract. 2006, 5, 135-144.

25. Izdebska J. N.: Nowe gatunki Demodex ssp. (Acari, Demodecidae) u Mus musculus w Polsce. Wiad. Parazytol. 2000, 46, 277-280. 
26. Izdebska J. N., Fryderyk S.: Diversity of three species of the genus Demodex (Acari, Demodecidae) parasitizing dogs in Poland. Pol. J. Env. Stud. 2011, 20, 565-569

27. Izdebska J. N., Rolbiecki L.: Demodex lutrae n. sp. (Acari) in European otte Lutra lutra (Carnivora: Mustelidae) with data from other demodecid mites in carnivores. J. Parasitol. 2014, 100, 784-789.

28. Izdebska J. N., Rolbiecki L.: Demodex microti n. sp. (Acari: Demodecidae) in Microtus arvalis (Pallas) (Rodentia, Cricetidae) with a checklist of the demodecid mites of cricetids. Sys. Parasitol. 2013, 86, 187-196.

29. Jarmuda S., O'Reilly N., Żaba R., Jakubowicz O., Szkaradkiewicz A., Kavanagh K.: Potential role of Demodex mites and bacteria in the induction of rosacea. J. Med. Microbiol. 2012, 61, 1504-1510.

30. Kadulski S., Izdebska J. N., Kończyk M.: Parasitic arthropods of Bison bonasus from the Białowieża primeval forest. Wiad. Parazytol. 1996, 42, 255-260.

31. Karaer Z., Kurtdede A., Ural K., Sari B., Cingi C. C., Karakurum M. C. Hyaderdedeoglu A. E.: Demodicosis in a Golden (Syrian) hamster (Mesocricetus auratus). Ank. Univ. Vet. Fak. Derg. 2009, 56, 227-229.

32. Karbowiak G., Demiaszkiewicz A. W., Pyziel A. M., Wita I., Moskwa B., Werszko J., Bień J., Goździk K., Lachowicz J., Cabaj W.: The parasitic fauna of the European bison (Bison bonasus) (Linnaeus, 1758) and their impact on the conservation. Part 1, The summarizing list of parasites noted. Acta Parasitol. 2014, 59, 363-371.

33. Kim K. T., Lee S. H., Kwak D.: Treatment of naturally acquired demodectic mange with amitraz in two harbour seals (Phoca vitulina). Acta Vet. Hung. 2016, 63, 352-357.

34. Kosik-Bogacka D. I., Eanocha N., Eanocha A., Czepita D., Grobelny A., Zdziarska B, Kalisińska E.: Demodex folliculorum and Demodex brevis in healthy and immunocompromised patiens. Ophtal. Epidemiol. 2013, 20, 159-163.

35. Lancey N., Kavangh K., Tseng S. C.: Under the lash: Demodex mites in human diseases. Biochem. 2009, 31, 2-6.

36. Lankton J., Chapman A., Ramsay E. C., Kania S. A., Newkirk K. M.: Preputial Demodex species in big brown bats (Eptesicus fuscus) in eastern Tennessee. J. Zoo Wild. Med. 2013, 44, 124-129.

37. Mathes R. L., Carmichael K. P., Peroni J., Moore P. A.: Primary lacrimal gland adenocarcinoma of the third eyelid in a horse. Vet. Ophtalm. 2011, 14, 48-54.

38. Mulugeta Y., Yacob H. T., Ashenafi H.: Ectoparasites of small ruminants in three selected agro-ecological sites of Tigray Region, Ethiopia. Trop. Anim. Health and Product. 2010, 42, 1219-1224.

39. Murray J. K.: Mange in Cattle: Demodectic Mange. Agri-Facts 2005, 6, 1-2

40. Ordeix L., Bardagi M., Scarampella F., Ferrer L., Fondati A.: Demodex inja infestation and dorsal greasy skin and hair in eight wirehaired fox terrier dogs. Vet. Dermatol. 2009, 20, 267-272.

41.Pereira A. V., Pereira S. A., Gremiao I. D., Campos M. P., Ferreira A. M. Comparison of acetate tape impression with squeezing versus skin scraping for the diagnosis of canine demodicosis. Austral. Vet. J. 2012, 90, 448-450.

42. Plumb D. C.: Plumb's Veterinary Drug Handbook, $6^{\text {th }}$ edition. Pharma Vet Inc. Stockholm 2008

43. Puacz E., Maciag E.: Demodex - patogen wart przypomnienia. Diagn. Labor 2012, 3, 14-15.
44. Rather P. A., Hassan I.: Human Demodex Mite: The Versatile Mite of Dermatological Importance. Ind. J. Dermatol. 2014, 59, 60-66.

45. Ravera I., Altet L., Francino O., Sanchez A., Roldan W., Villanueva S., Bardagi M., Ferrer L.: Small Demodex populations colonize most parts of the skin of healthy dogs. Vet. Dermatol. 2013, 24, 168-172.

46. Rejas L. J., Diez R. R., Diez B. N.: First report of canine demodicosis by shortbodied Demodex Mite (Acari: Demodicidae) in Spain. Rev. Ibero-Latinoamer. Parasitol. 2011, 70, 219-224.

47. Rojas M. de, Riazzo C., Callejon R., Guevara D., Cutillas C.: Molecular study on three morphotypes of Demodex mites (Acarina: Demodicidae) from dogs. Parasitol. Res. 2012, 111, 2165-2172.

48. Rusiecka-Ziótkowska J., Nokiel M., Fleischer M.: Demodex - An old pathogen or a new one? Adv. Clin. Exp. Med. 2014, 23, 295-298.

49. Saari S. A. M., Juuti K. H., Palojarvi J. H., Vaisanen K. M., Rajaniemi R., Saijonmaa-Koulumies L. E.: Demodex gatoi-associated contagious pruritic dermatosis in cats - a report from six households in Finland. Acta Vet. Scand. 2009, 51, 1-8.

50. Saridomichelakis M., Koutinas A., Papadoginnakis E., Papazachariadou M., Liapi M., Trakas D.: Adult-onset demodicosis in two dogs due to Demodex canis and a short-tailed demodectic mite. J. Small Anim. Pract. 1999, 40, 529.

51. Silbermayr K., Horvath-Ungerboeck C., Eigner B., Joachim A., Ferrer L. Phylogenetic relationship and the new genetic tools for the detection and discrimination of the three feline Demodex mites. Parasitol. Res. 2015, 114 747-752.

52. Silbermayr K., Joachim A., Litschauer B., Panakova L., Sastre N., Ferrer L., Horvath-Ungerboeck $C .:$ The first case of Demodex gatoi in Austria, detected with fecal flotation. Parasitol. Res. 2013, 112, 2805-2810.

53. Sivajothi S., Reddy B. S., Rayulu V. C.: Demodicosis caused by Demodex canis and Demodex cornei in dogs. J. Parasit. Dis. 2015, 39, 673-676.

54. Tarkowski W., Moneta-Wielgoś J., Mlocicki D.: Demodex sp. as a potential cause of the abandonment of soft contact lenses by their existing users. BioMed Research International. Article ID 259109, 7 pages, 2015. doi: $10.1155 / 2015 / 259109$.

55. Tarkowski W., Owczyńska M., Błaszczyk-Tyszka A., Młocicki D.: Demodex mites as a potential etiological factor in chalazion - a study in Poland. Acta Parasitol. 2015, 60, 777-783.

56. Tarkowski W., Owczyńska M., Błaszczyk-Tyszka A., Młocicki D.: Nużeniec jako czynnik etiologiczny przewlekłego zapalenia brzegów powiek - problem wciąż niedoceniany. Mag. Lek. Okul. 2015, 9, 65-66.

57. Wesołowska M., Knysz B., Reich A., Blazejewska D., Czarnecki M., Gladysz A., Pozowski A., Misiuk-Hojlo M.: Prevalence of Demodex spp. in eyelash follicles in different populations. Arch. Med. Scien. 2014, 10, 319-324.

58. Yeruham I., Rosen S., Hadani A.: Sheep demodicosis (Demodex ovis Railliet, 1895) in Israel. Revue d Elevage et de Medecine Veterinaire des Pays Tropicaux 1986, 39, 363-365

59. Zhao Y., Cheng J., Hu L., Ma J.: Molecular identification and phylogenetic study of Demodex caprae. Parasitol. Res. 2014, 113, 3601-3608.

Corresponding author: vet. Surg. Dawid Jańczak, National Institute of Public Health, Division of Parasitology, Chocimska 24, 00-791 Warsaw, Poland; e-mail: djanczak@pzh.gov.pl 